\title{
Article \\ Study on Mechanical Characteristics and Failure Modes of Coal-Mudstone Combined Body with Prefabricated Crack
}

\author{
Huayong Lv ${ }^{1,+}$, Defeng Wang ${ }^{2}$, Zhanbo Cheng ${ }^{3, *}$, Yaning Zhang ${ }^{4, \dagger}$ and Tao Zhou ${ }^{5}$ \\ 1 School of Architecture and Engineering, Shangqiu Normal University, Shangqiu 476000, China; \\ lvhuayong@sqnu.edu.cn \\ 2 Institute of Mining and Special Civil Engineering, Technical University Bergakademie Freiberg, \\ 09599 Freiberg, Germany; defeng.wang@doktorand.tu-freiberg.de \\ 3 School of Engineering, University of Warwick, Coventry CV4 7AL, UK \\ 4 China Coal Research Institute, Beijing 100013, China; yaningzhang@hotmail.com \\ 5 School of Foreign Languages, Shangqiu Normal University, Shangqiu 476000, China; \\ zhoutao20001001@163.com \\ * Correspondence: Z.Cheng.4@warwick.ac.uk; Tel.: +44-07563935629 \\ + These authors contributed equally to this work.
}

check for

updates

Citation: Lv, H.; Wang, D.; Cheng, Z.;

Zhang, Y.; Zhou, T. Study on

Mechanical Characteristics and

Failure Modes of Coal-Mudstone

Combined Body with Prefabricated

Crack. Mathematics 2022, 10, 177.

https://doi.org/10.3390/

math10020177

Academic Editor:

Efstratios Tzirtzilakis

Received: 15 November 2021

Accepted: 27 December 2021

Published: 7 January 2022

Publisher's Note: MDPI stays neutral with regard to jurisdictional claims in published maps and institutional affiliations.

Copyright: (C) 2022 by the authors. Licensee MDPI, Basel, Switzerland. This article is an open access article distributed under the terms and conditions of the Creative Commons Attribution (CC BY) license (https:// creativecommons.org/licenses/by/ $4.0 /)$.

\begin{abstract}
There are normally pre-existing cracks that can be observed in the coal seam and immediate roof that influences the stability of the rib spalling and the movement law of overlying strata. In this study, comprehensive research methods (e.g., theory analysis, experimental tests and numerical simulations) were adopted to reveal the mechanical characteristics, acoustic emission behaviors and failure modes of a coal-mudstone combined body with a single prefabricated non-penetrating crack. The results show that the influence of the crack angle on the elastic modulus of the coalmudstone combined body samples was limited. With the increase in the crack angle, the unconfined compressive strength of samples decreased first and then increased in a V-shaped trend. In addition, the minimum unconfined compressive strength could be observed at a crack angle of $45^{\circ}$. Moreover, the number of acoustic emissions significantly increased with the process of continuous loading. In addition, the stress reduction zone could be observed in both ends of the prefabricated cracks at the initial stage of loading. The high- and low-stress zones were transformed with the process of continuous loading. Under an unconfined compression test, the failure models of the coal body part in the samples were mainly caused by shear failure, and only a few cracks occurred in the upper tip of the prefabricated cracks of the mudstone part. Therefore, airfoil cracks could be observed in the samples due to the strength difference of the coal mass and mudstone.
\end{abstract}

Keywords: unconfined compressive strength; crack propagation; coal-mudstone combined body; failure modes

\section{Introduction}

Many cracks can normally be observed in the coal seam and rock under the impact of the geological structure or mining activities. Naturally oriented fractures can significantly decrease the mechanical properties (e.g., strength, stiffness and elastic modulus) of the coal mass and rock. Therefore, the mechanical behaviors and failure laws of the coal and rock mass mainly depend on the distribution and development of cracks, which can cause serious engineering disasters, such as rib spalling, roof falling, rock burst and landslides [1-5]. In recent decades, gaining a comprehensive understanding of the mechanical behaviors of coal and rock masses with various faults (e.g., pre-existing cracks or holes) has been attractive [6-13]. Specifically, experimental tests had normally been performed on pre-existing cracks in rock to illustrate mechanical behaviors [14-17]. Wong et al. [18,19] illustrated the failure modes and mechanical properties of sandstone-like materials with parallel cracks using a uniaxial compression test. Li et al. [20] analyzed the influence of 
end-crack morphology on rock dynamic mechanical properties and crack propagation of prefabricated cracks with different dip angles in marble samples. Yang et al. [21] explored the influence of confining pressure to the crack propagation and fracture mode of rock samples and established a mechanical model of crack propagation based on fracture mechanics theory. Through uniaxial and triaxial compression tests of pre-cracked specimens, cracks initiated in the form of tensile cracks and ultimate failure modes were dominantly caused by tensile cracks combined with shear cracks. Li et al. [22] found that the UCS and elastic modulus of coal specimens decreased with the occurrence of a single crack by employing RFPA2D. Tang [23] illustrated the gradually evolving strain and stress fields, the characteristics of acoustic emission and the modes of failure propagation of rock specimens with single and multiple cracks in the process of crack development by using RFPA2D. Moreover, the crack inclination angle significantly impacts the mechanical behaviors and failure mode of rock samples with the occurrence of single and double cracks [24]. Lv et al. [25] illustrated the UCS of coal specimens with a single non-penetrating crack, which decreased first and then increased with an increase in the crack angle. The minimum UCS was obtained when the crack angle was at $45^{\circ}$. In addition, the occurrence of holes in a coal mass can significantly decrease the mechanical parameters of the coal mass, and it is closely related to the geometry and diameter of prefabricated holes and the distribution parameters of cracks $[26,27]$.

Under a large and deep mining workface with high stress, mining disasters normally occur due to the sudden failure and instability of the coal-rock combined body. Conversely, the top coal-immediate roof is regarded as a cushioning layer to resist the overburden in the mining process of a top coal caving mining workface. The mechanical properties of the combined body can significantly influence the relationship between the support and surrounding rock. The stability determination of a two-body system composed of a roof, a floor and coal was first proposed by Petukhov and Linkov [28]. The "roof-coal body-floor" system was proposed to explore the post-peak stability of rock materials. In recent years, the burst potential and energy dissipation of coal-rock combined bodies have been comprehensively illustrated by using acoustic emission and infrared thermal imaging. Wang et al. [29] performed a double-shear frictional test under biaxial loading and illustrated the space-time evolution of the displacement field as well as AE characteristics during sliding. Zuo et al. [30] illustrated the mechanical properties and failure characteristics of different coal-rock combined bodies and their influence on bursting stability. Xie et al. [31] proposed a two-body mechanical model based on the interaction between a geological body and engineering body. It was preliminary to discuss the failure mechanism of a two-body interaction and its difference from the one-body, two-medium mechanical model. Zhao et al. [32] analyzed the law of energy accumulation and release and the strain variation in the different parts of a coal-rock combined body during the loading process. The instability law and predicted failure information of a coal-surrounding rock system were obtained. Gong et al. [33] found that there were double-peak features under high loading rates through the entire dynamic stress-strain curves, which can be divided into four stages. Cheng et al. [34] comprehensively illustrated the influence of the coal-rock height ratio, coal and rock mass behavior and interface parameters on the mechanical properties of a coal-rock combined body through uniaxial compressive strength. The relevant results were also consistent with other references [35-39]. Liu et al. [40] used a two-body interaction theory and RFPA2D numerical simulation to illustrate the deformation and fracture process of a coal-rock combined body. Wang and Tian [35] used numerical simulations to explore the mechanical properties, crack evolution characteristics and propagation forms of the initial and final crack distribution of coal-rock specimens with different fracture holes. They concluded that the crack angle significantly influenced the mechanical behaviors of the coal-rock combined body.

Throughout the literature, the existing research mainly focused on the mechanical properties of a single coal mass or rock. However, these cannot fully reflect the stability of a working face and the movement law of overlying strata. Therefore, it is more reasonable 
and accurate to take the coal seam and overlying strata as a whole. The mechanical properties of a coal-rock combined body can influence the safety and efficiency of mining. Although there are a few studies on the mechanical properties and failure modes of coalrock combined bodies with different combination types, they do not normally consider the influencing factor of pre-existing cracks. In this study, with the selection of mudstone as the typical composite of the immediate roof layer, an unconfined compression test was performed to explore the mechanical properties and failure modes of a coal-mudstone combined body with different angles of a single prefabricated crack. Moreover, RFPA2D was adopted to simulate the whole process of an unconfined compression test to verify the results of the unconfined compressive strength and failure modes in experimental tests. In addition, it can also further explore the stress evolution, crack propagation and acoustic emission evolution of the coal-mudstone combined body. The research results can provide a solid theoretical basis for revealing the failure mechanisms of coal-rock combined bodies with pre-existing cracks to prevent and control relevant mine disasters.

\section{Experimental Tests}

\subsection{Specimen Preparation and Experimental Methods}

The mudstone and coal masses were prepared by using coal powder/sand, cement and water with a certain ratio. The ratio of coal powder, cement and water in the coal mass was 1:1:0.67, while the ratio of sand, cement and water in the rock mass was 1:1.5:1. For creating the uniform unconfined compression test specimens, the homogeneity distribution mixtures were poured into cylinder molds with a diameter of $50 \mathrm{~mm}$ and height of $100 \mathrm{~mm}$. Meanwhile, a thin slice was inserted into the molds to form the prefabricated crack, with a length and width of $40 \mathrm{~mm}$ and $1 \mathrm{~mm}$, respectively. As shown in Figure 1, the crack angle $(\theta)$ was selected as $0^{\circ}, 15^{\circ}, 30^{\circ}, 45^{\circ}, 60^{\circ}, 75^{\circ}$ and $90^{\circ}$. In addition, an intact specimen was also created as a reference. In all specimens, the height ratio of mudstone to coal was set as 1:1. Therefore, the prepared specimens had the advantages of high homogeneity and a controllable crack angle. The physical and mechanical parameters of the mudstone and coal masses in this study are shown in Table 1 , and they were similar to natural coal and rock materials.

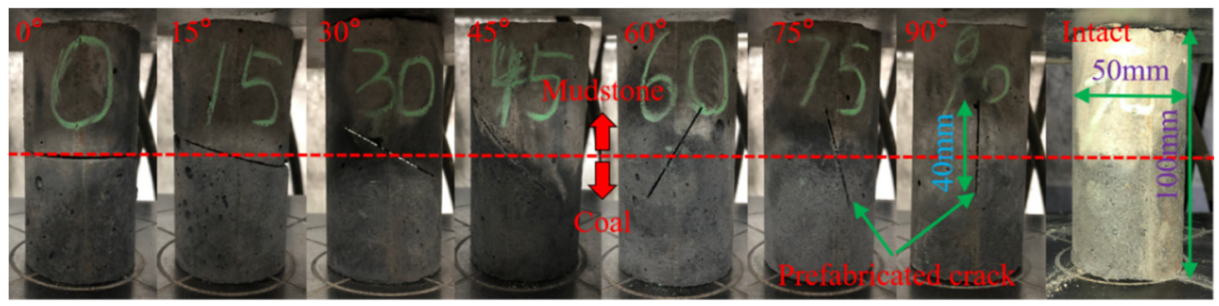

Figure 1. Coal-mudstone specimens with different prefabricated crack angles.

Table 1. Physical and mechanical parameters of coal and mudstone masses.

\begin{tabular}{|c|c|c|c|c|c|c|c|c|}
\hline Lithology & $\begin{array}{c}\text { Macro } \\
\text { Elastic } \\
\text { Model/MPa }\end{array}$ & $\begin{array}{c}\text { Macro } \\
\text { Strength/MPa }\end{array}$ & $\begin{array}{l}\text { Mean Elastic } \\
\text { Modulus/MPa }\end{array}$ & $\begin{array}{c}\text { Mean } \\
\text { Intensity/MPa }\end{array}$ & $\begin{array}{l}\text { Compression } \\
\text { Tension Ratio }\end{array}$ & $\begin{array}{l}\text { Friction } \\
\text { Angle } /^{\circ}\end{array}$ & $\begin{array}{c}\text { Poisson } \\
\text { Ratio }\end{array}$ & $\begin{array}{c}\text { Homogeneity } \\
\text { Coefficient }\end{array}$ \\
\hline Mudstone & 6000 & 15.2 & 7389 & 46.6 & 10 & 30 & 0.3 & 3.2 \\
\hline Coal & 4000 & 10.8 & 4981 & 34.9 & 15 & 25 & 0.28 & 3 \\
\hline
\end{tabular}

As shown in Figure 2, a TAW 2000 microcomputer-controlled hydraulic servo press, consisting of a specimen loading system, hydraulic system, control system and data acquisition, was adopted in this study. The unconfined compression test was conducted under a strain-controlled condition at a loading rate of $0.5 \% / \mathrm{min}$ in accordance with ASTM D2166. In addition, during the loading process, a high-speed camera was used to record the process of cracks germinating, expanding and gathering and the joining up of microfissures 
until the specimen completely failed. Through the data acquisition and control system, the force displacement image was displayed on the computer screen in real time, and the data could also be exported to obtain the stress-strain curve of each specimen by using Origin. Moreover, for eliminating errors in the experimental processes, three replicates of each condition were performed to calculate the average values.

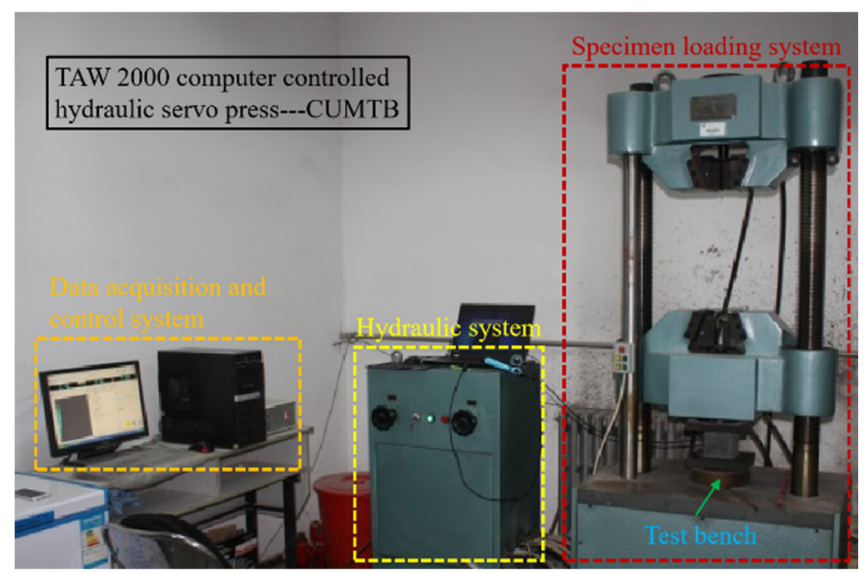

Figure 2. Experimental apparatus.

\subsection{Results}

\subsubsection{Stress-Strain Behaviors}

Figure 3 shows the typical stress-strain curves of coal-mudstone specimens with different prefabricated crack angles. It can be observed that the slope of specimens with the occurrence of a prefabricated crack angle in the stage of elastic deformation was basically the same as that of the intact specimen. This indicates that the occurrence of a crack and its angle have limited influence on the elastic modulus of the coal-mudstone combined body. Moreover, the axial strain obtaining the maximum unconfined compressive strength of specimens with the occurrence of a prefabricated crack was smaller than that of the intact specimen. Additionally, with the increase in the prefabricated crack angle, the strain decreased first and then increased. Normally, all stress-strain curves slowly rise after the stage of elastic deformation, followed by a short period of the quadratic elastic deformation stage. This can be explained by the fact that the mudstone body part is still in the linear elastic deformation stage and has not completely failed, although the coal body part reaches the yield strength and enters the plastic stage.

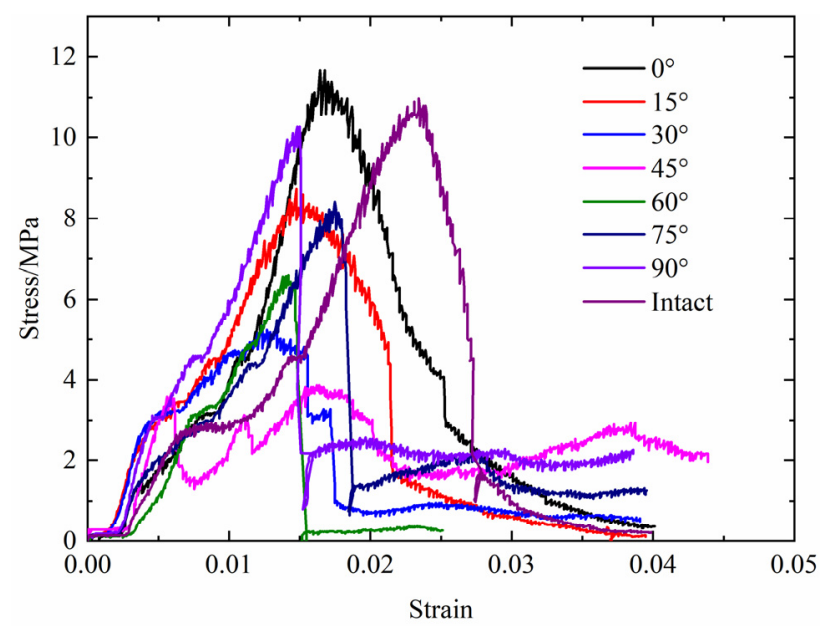

Figure 3. Stress-strain curves of specimens with different prefabricated crack angles. 


\subsubsection{Failure Processes and Characteristics}

Figure 4 shows all of the failure processes of specimens with different prefabricated crack angles and changing times. Obviously, the prefabricated crack gradually closed with the increase in loading displacement when the prefabricated crack angle $(\theta)$ was $0^{\circ}$. Additionally, compression shear failure could be observed in both ends of the prefabricated crack. After the crack was completely closed, the unconfined compressive strength (UCS) of the coal-rock combined body reached the maximum value. With the continuous loading, the UCS of the specimen decreased sharply with the occurrence of tensile and shear failure in the lower coal body, which resulted in the formation of several new near-vertical tensile cracks. In addition, the upper rock body near the crack was mainly shear failure. At $\theta=15^{\circ}$, the failure processes of the specimen were basically consistent with those of $\theta=0^{\circ}$, before the UCS reached the maximum value. However, after that, the UCS of the specimen decreased sharply with the occurrence of overall tensile and shear failure in the whole specimen, which resulted in multiple near-vertical tensile cracks running through the prefabricated crack. At $\theta=30^{\circ}$, the prefabricated crack also firstly closed, and compression shear failure could be observed in both ends of the prefabricated crack during the closure process. After that, the UCS of the specimen began to decrease with the tensile and shear failure of the specimen, and the prefabricated crack continued to expand to both ends of the specimen, resulting in the generation of new inclined main shear cracks. At $\theta=45^{\circ}$, compression shear failure could be observed in both ends of the prefabricated crack. After the crack closed completely, tensile shear failure in the lower coal body occurred with the formation of two main shear cracks. Moreover, one main shear crack was generated in the upper mudstone body. With the continuous loading, these cracks were further extended and accompanied by the sliding failure of the specimen along the direction of the prefabricated crack. Additionally, with the continuous increase in the prefabricated crack angle to $60^{\circ}$ and $75^{\circ}$, the sliding failure of the specimen along the direction of the prefabricated crack was more obvious. Additionally, three main shear fractures were formed in both ends of the specimen with $\theta=60^{\circ}$, while tension failure finally occurred in both ends of the specimen with $\theta=75^{\circ}$. At $\theta=90^{\circ}$, the prefabricated crack was vertically extended to both ends of the specimen to form a main tensile fracture.

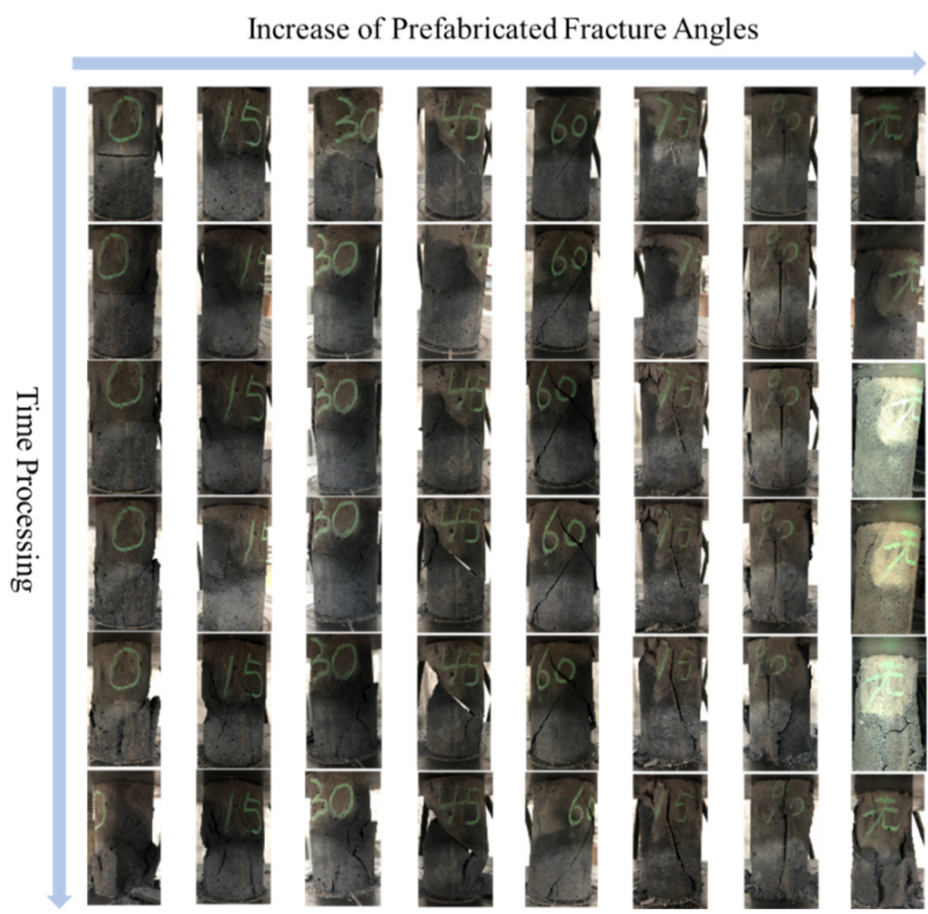

Figure 4. Failure processes and characteristics of specimens. 


\section{Numerical Simulation}

\subsection{Basic Concepts of RFPA}

RFPA (rock failure process analysis) is a numerical calculation method of material failure process analysis based on finite element stress analysis and elastic damage theory. The whole working flow of RFPA is shown in Figure 5. For each given displacement increment, the stress and strain of each element can be calculated, and then the program can be transferred to phase transition analysis, which can be regarded as the checking stage regarding whether there is a phase transition in each element based on the phase transition criterion $[13,26]$. If not, a displacement component increases for the next stress calculation under continuous loading. If there is the occurrence of a phase transition in an element, the phase transition element will be treated by weakening the stiffness characteristics (e.g., crack or separation) or reconstructing the stiffness (e.g., compaction or contact) according to the type of phase transition, as shown in Figure 6. Subsequently, the stress and strain calculation of the current step is carried out again until no new phase transition element appears. Finally, the new physical and mechanical parameters of each element are formed for iterative calculation of the whole medium. The above processes are repeated until the applied loading and deformation cause a macro-fracture of the whole medium.

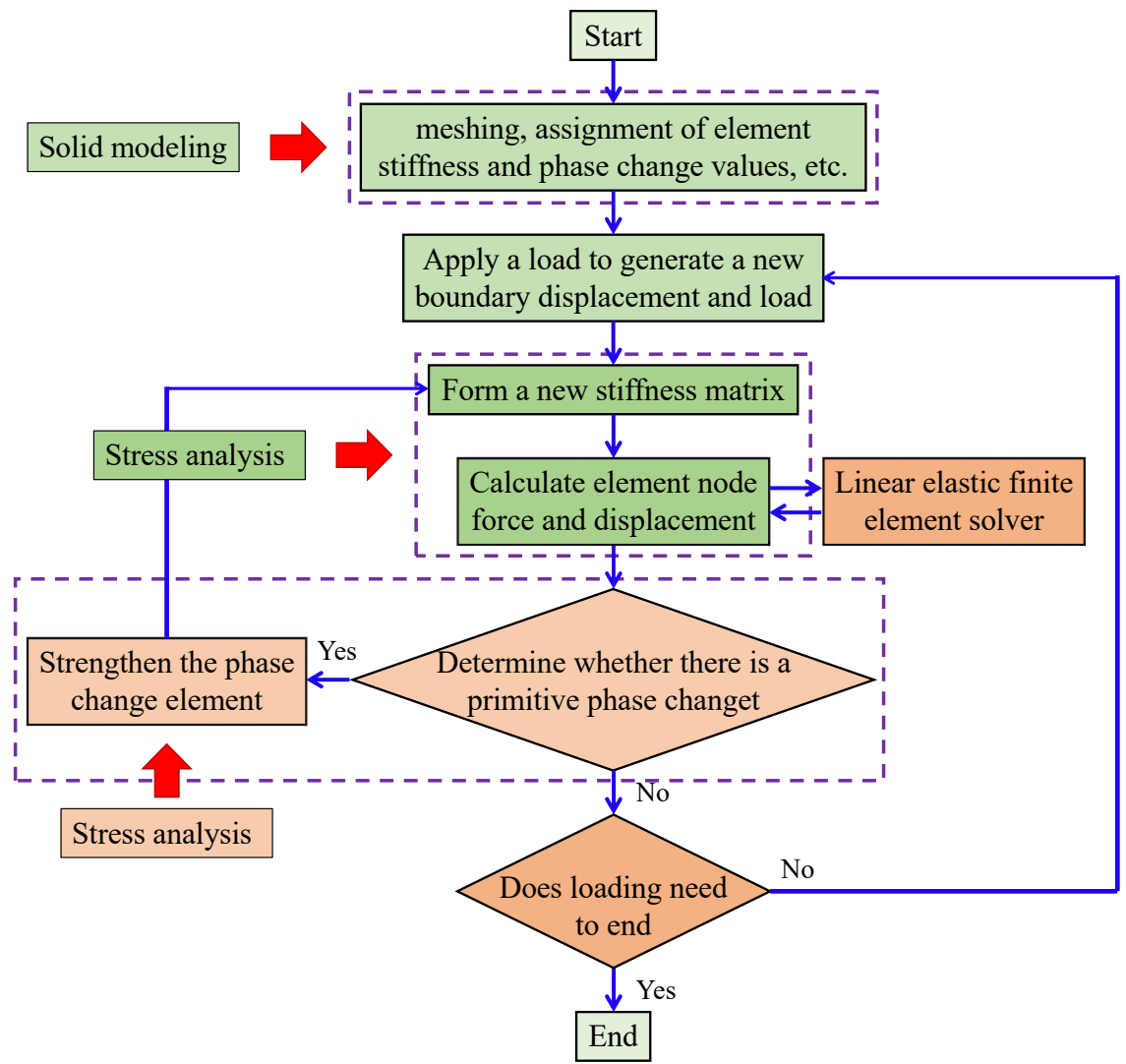

Figure 5. Failure processes and characteristics of specimens. 


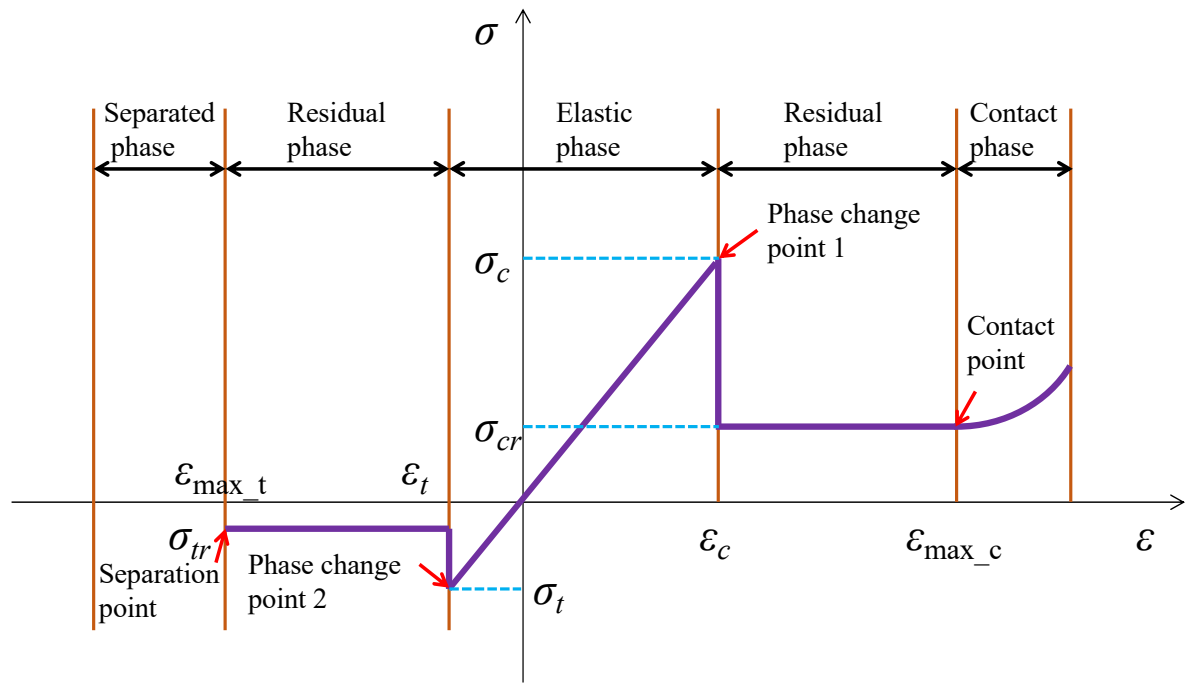

Figure 6. Phase transition of elements.

\subsection{Model Establishment}

As shown in Figure 7, RFPA2D was adopted to build the coal-rock combined models, with a length of $100 \mathrm{~mm}$ and a width of $50 \mathrm{~mm}$. The pre-existing crack was set up with a length of $40 \mathrm{~mm}$ and a width of $1 \mathrm{~mm}$. Additionally, the whole model was divided into $200 \times 100$ grids. In terms of prefabricated crack angles, they were consistent with the experiment test conditions. The micro-mechanical parameters of the coal and mudstone masses were calculated from the macro-mechanical parameters of the experiment results, as shown in Table 2. In all specimens, the Mohr-Coulomb criterion and plane stress model were selected. In addition, the displacement increment was $0.02 \mathrm{~mm}$ each step because the stress-strain curves under this condition were consistent with the results of the experimental tests.

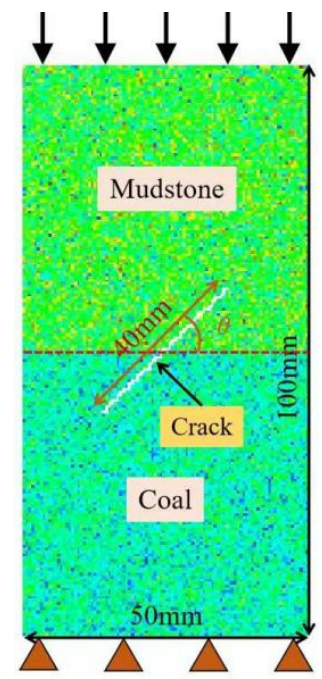

Figure 7. Numerical model.

Table 2. Micro-mechanical parameters of specimen.

\begin{tabular}{cccccc}
\hline $\begin{array}{c}\text { Homogeneous } \\
\text { Degree }\end{array}$ & $\begin{array}{c}\text { Mean Elastic } \\
\text { Modulus/MPa }\end{array}$ & $\begin{array}{c}\text { Mean Compressive } \\
\text { Strength/MPa }\end{array}$ & Poisson Ratio & Friction Angle/ ${ }^{\circ}$ & Pressure Rabbi \\
\hline 2 & 1333 & 39 & 0.3 & 35 & 15 \\
\hline
\end{tabular}




\subsection{Result Analysis}

\subsubsection{Stress Evolution Behaviors}

Figure 8 shows the stress evolution processes of coal-rock combined specimens with different prefabricated crack angles. At $\theta=0^{\circ}$, the stress reduction zone appeared in both ends of the prefabricated crack with a horn shape. Additionally, the rest areas can be regarded as high-stress zones at the initial loading stage. With the continuous loading, the UCS of the combined body sharply decreased with the transformation of the high-stress zone and the low-stress zone. Additionally, the stress concentration zone could be observed in both ends of the prefabricated crack, resulting in the failure of basic elements. After that, the high-stress zone continued to be expanded and transferred with the expansion and extension of the prefabricated crack. In this process, the basic elements around the crack gradually failed, and the stress of the whole specimen was in a low state until the combined body completely failed. In most cases, the stress evolution behaviors of the combined body with different prefabricated cracks were similar to the above description. However, at the initial loading stage, the low-stress region in both ends of the prefabricated crack gradually expanded with the increase in the prefabricated crack angle, while the surrounding high-stress region shrank. With the continuous loading, the high-stress zone and the low-stress zone were still transformed. However, the transformation phenomenon obviously weakened at $\theta=75^{\circ}$ and $\theta=90^{\circ}$. Additionally, the overall stress remained in a high state in the intermediate stage of loading until the specimens completely failed. In terms of the intact specimen, the stress evolution behaviors were similar to those of the combined body with $\theta=90^{\circ}$. However, there was no stress concentration in the intact specimen at the initial stage because there was no occurrence of a prefabricated crack in the intact specimen.
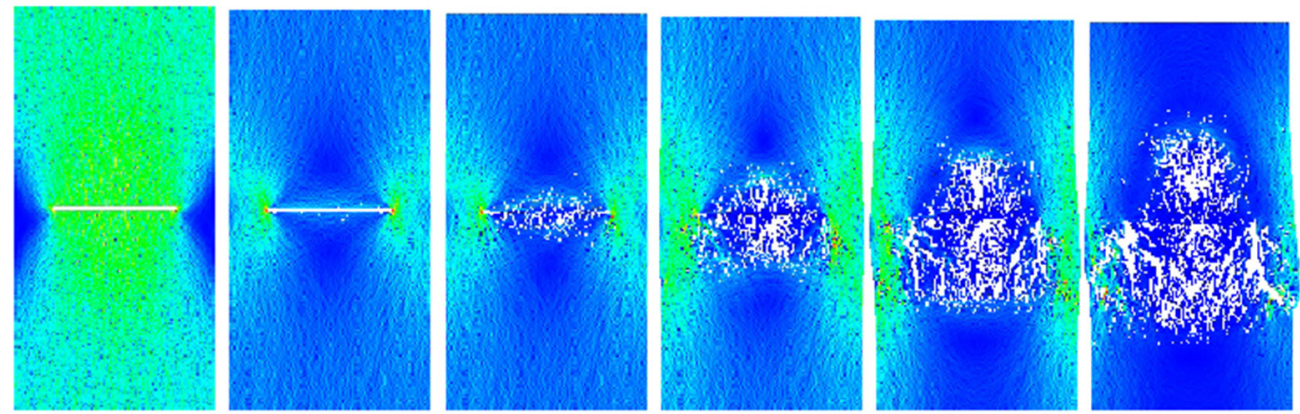

(a)
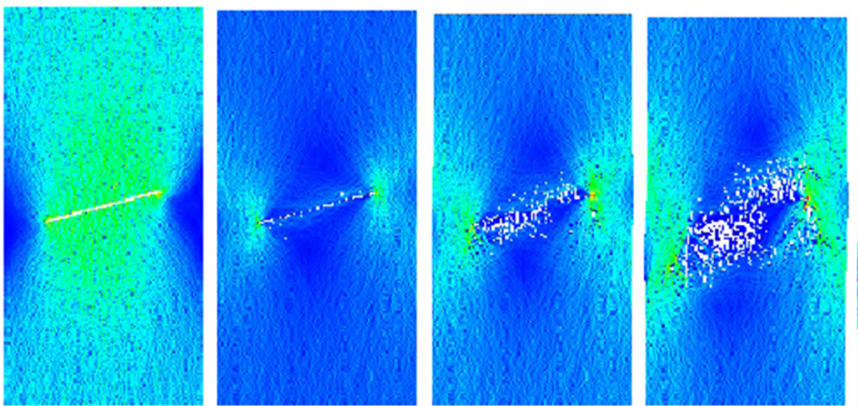

(b)
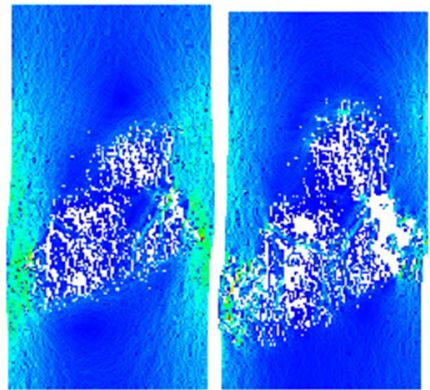

Figure 8. Cont. 

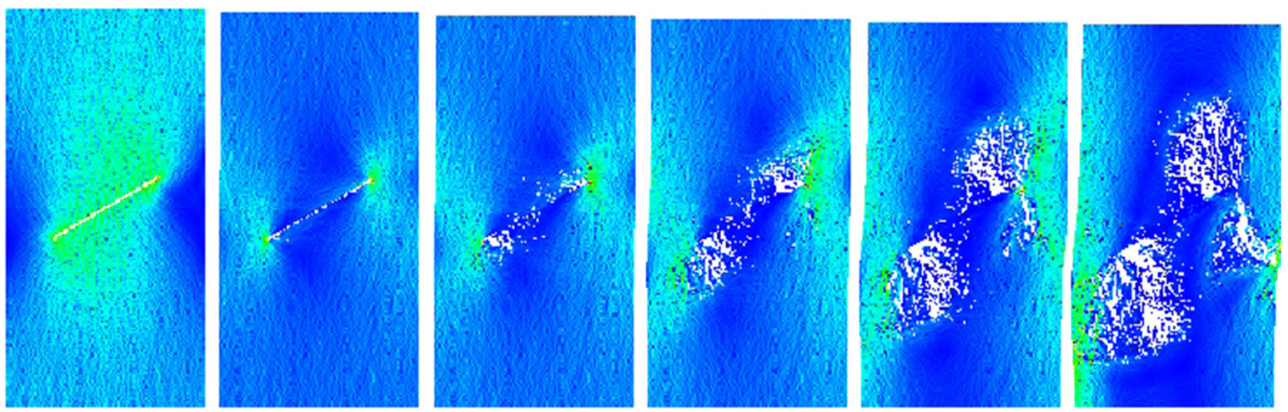

(c)
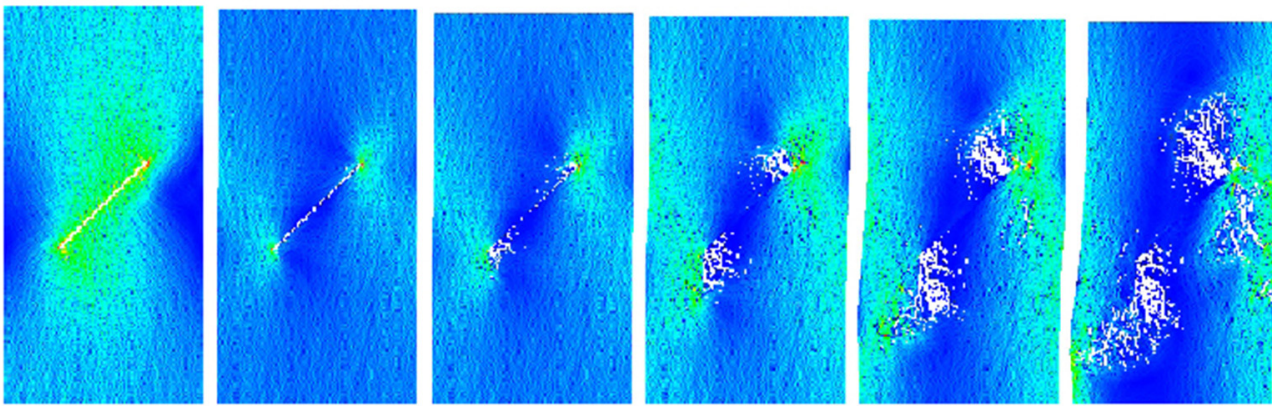

(d)
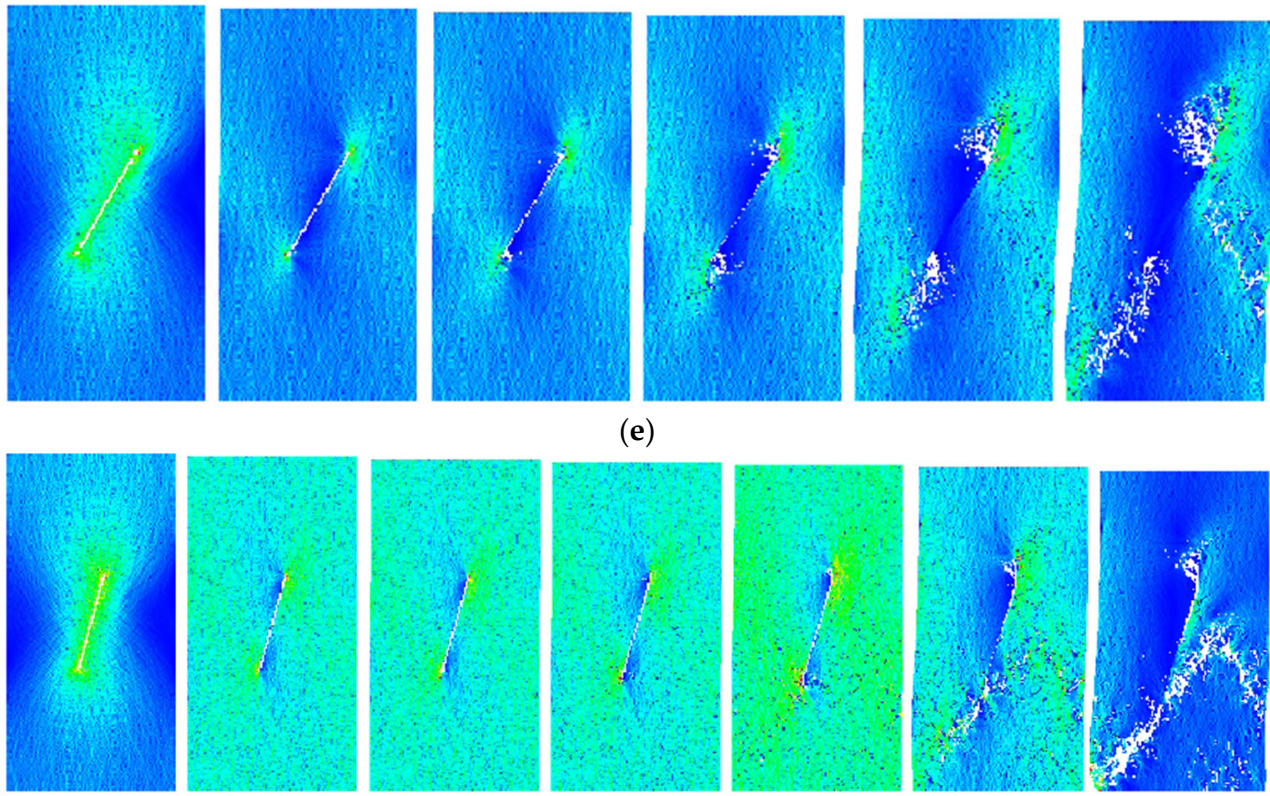

(e)
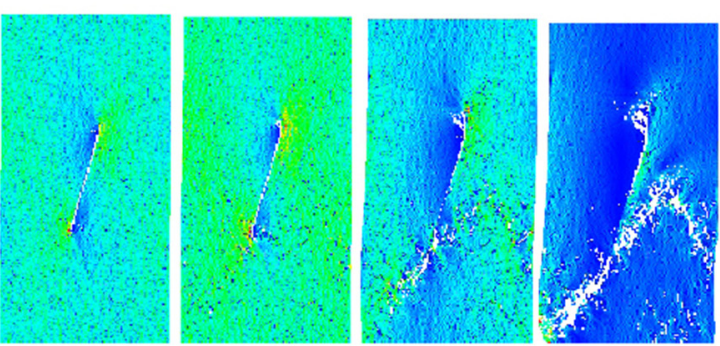

(f)
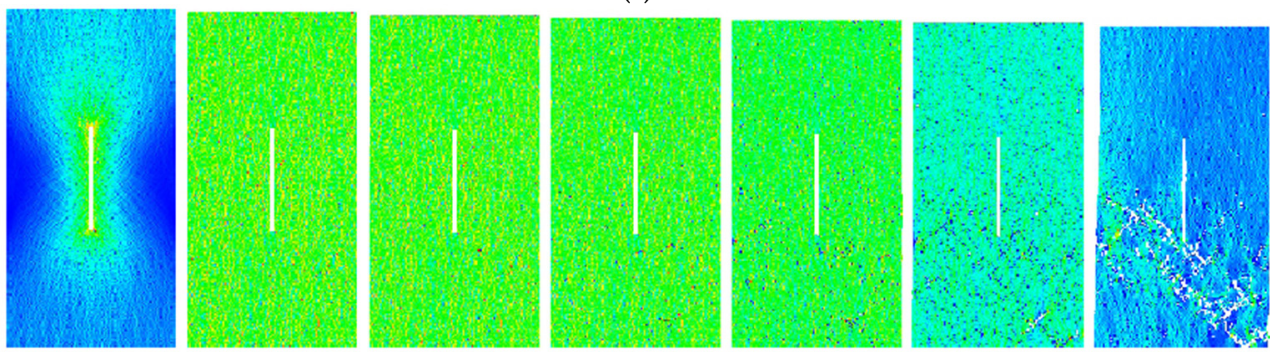

(g)

Figure 8. Cont. 

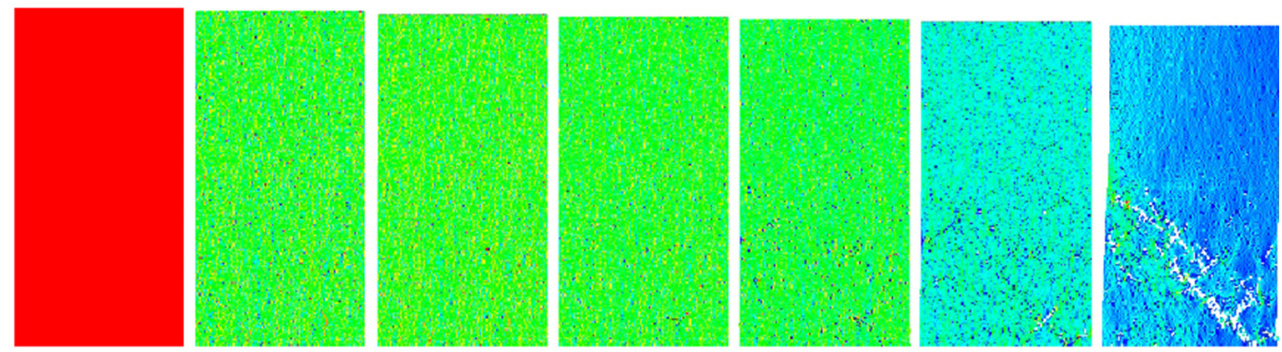

(h)

Figure 8. Stress evolution of coal-rock specimens with different prefabricated crack angles: (a) $\theta=0^{\circ}$; (b) $\theta=15^{\circ}$; (c) $\theta=30^{\circ}$; (d) $\theta=45^{\circ}$; (e) $\theta=60^{\circ}$; (f) $\theta=75^{\circ}$; (g) $\theta=90^{\circ}$; (h) intact specimens.

\subsubsection{Acoustic Emission (AE) Evolution Behaviors}

Figure 9 illustrates the acoustic emission evolution behaviors of the coal-rock combined body with different prefabricated crack angles. Additionally, the white and red circles represent tensile failure and shear failure, respectively. It can be observed that the acoustic emission appeared in both ends of the prefabricated crack at the initial loading stage when $\theta$ was in the range from $0^{\circ}$ to $45^{\circ}$. With the continuous loading, the acoustic emission was more obvious with the increase in the acoustic emission number, indicating that the consumed energy increased with the gradual failure of the coal-rock combined body. Moreover, tensile failure mainly occurred around the crack and in the lower coal body, while the distribution of shear failure was relatively uniform in all of the specimens. However, when $\theta$ was in the range from $60^{\circ}$ to $90^{\circ}$, the distribution of tensile failure was relatively uniform in all of the specimens, while shear failure could be mainly observed in the lower coal body. In terms of the intact specimen, it was found that tensile failure and shear failure mainly occurred in the upper rock body and the lower coal body, respectively.
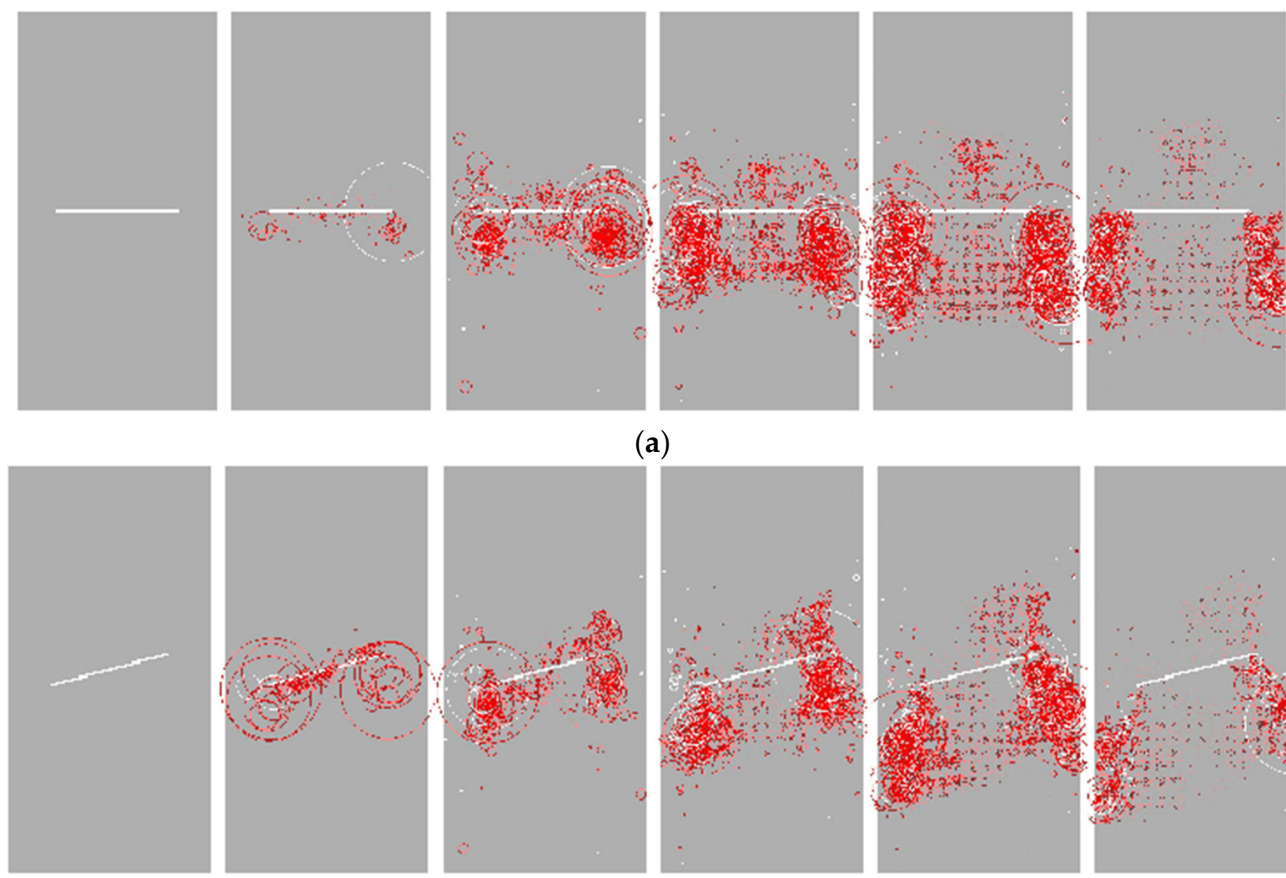

(a)
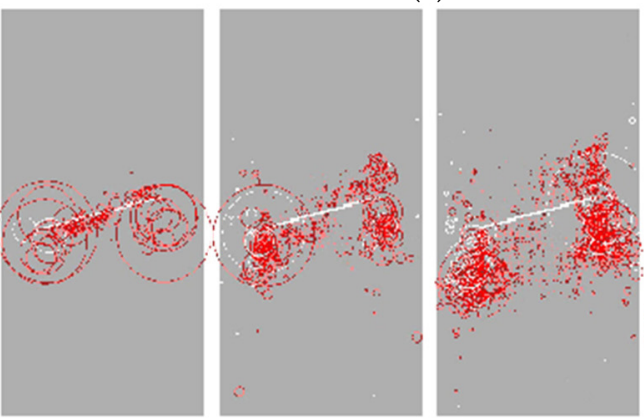

(b)
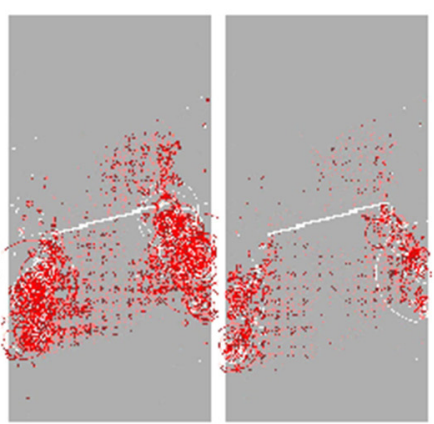

Figure 9. Cont. 

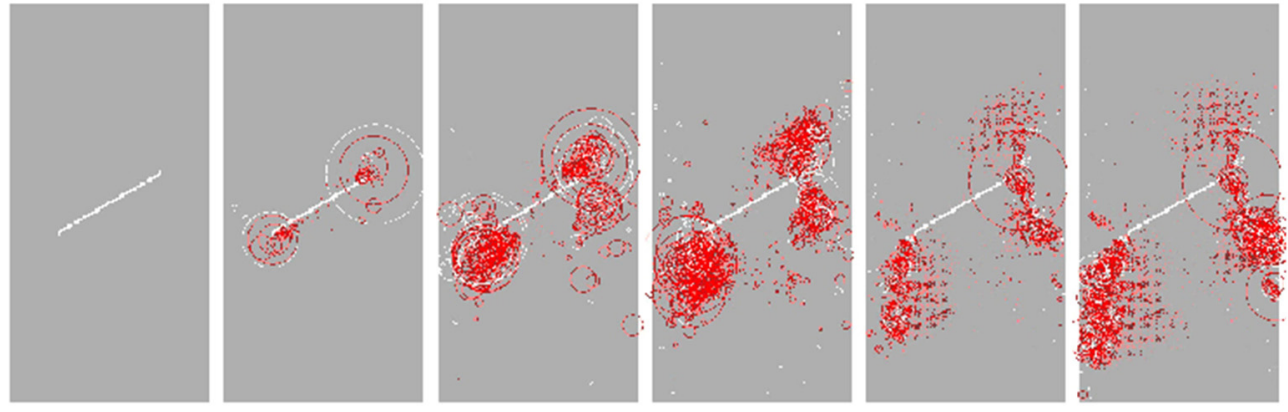

(c)
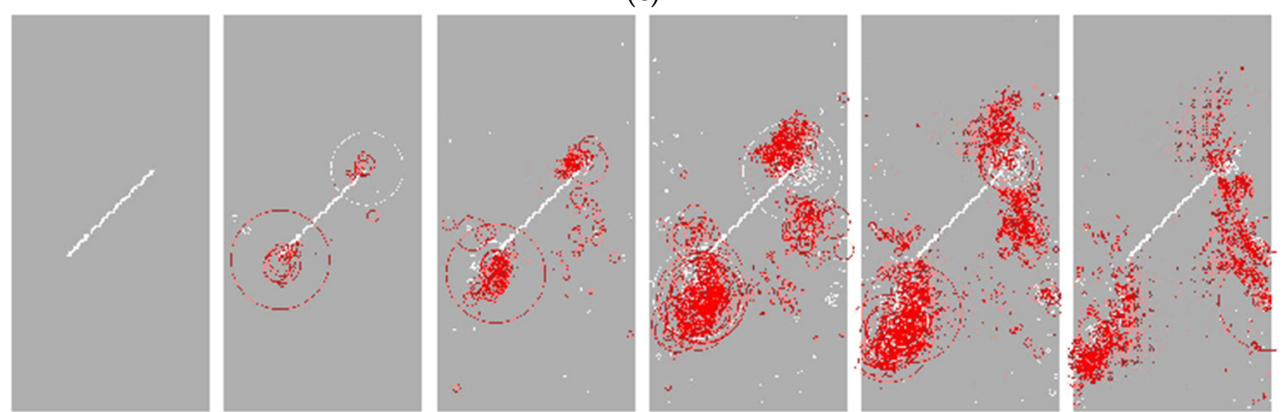

(d)
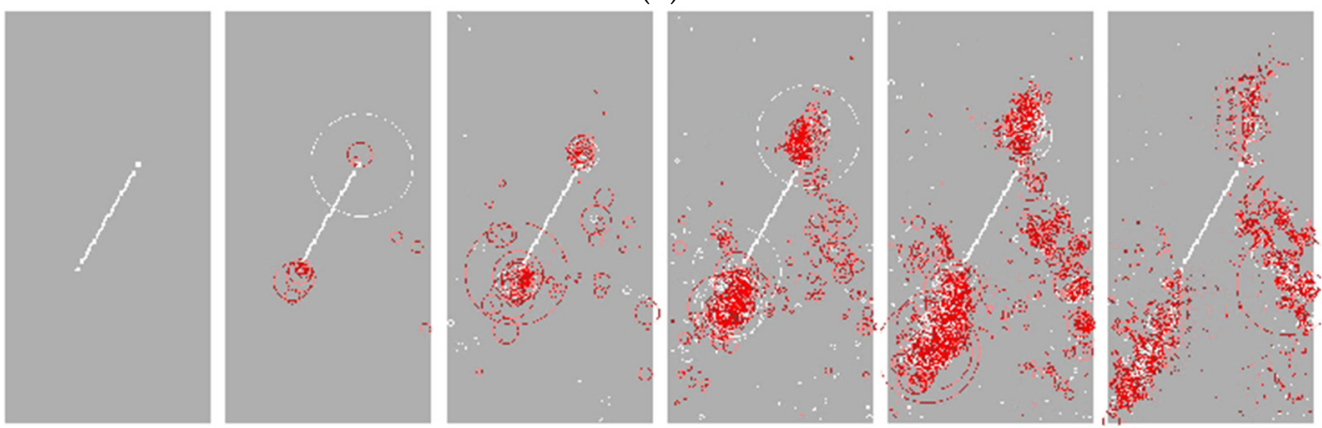

(e)
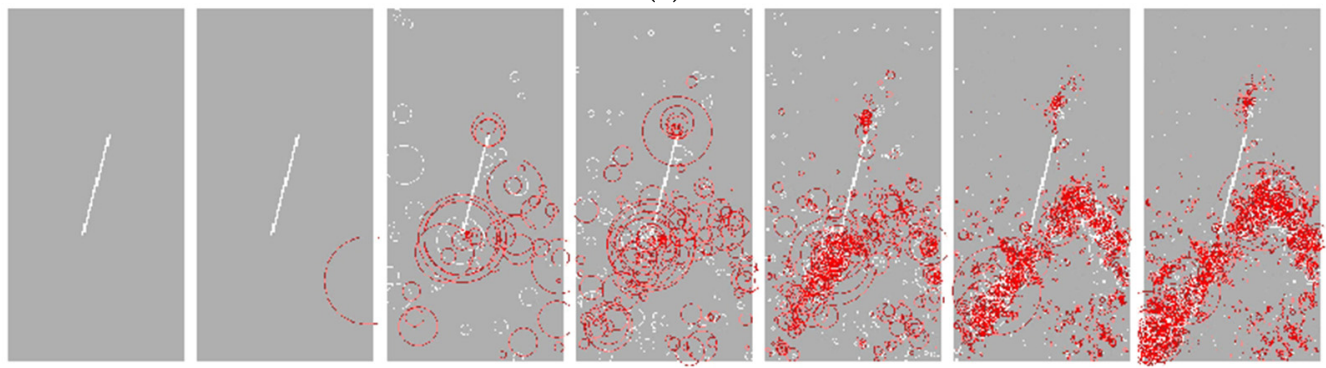

(f)
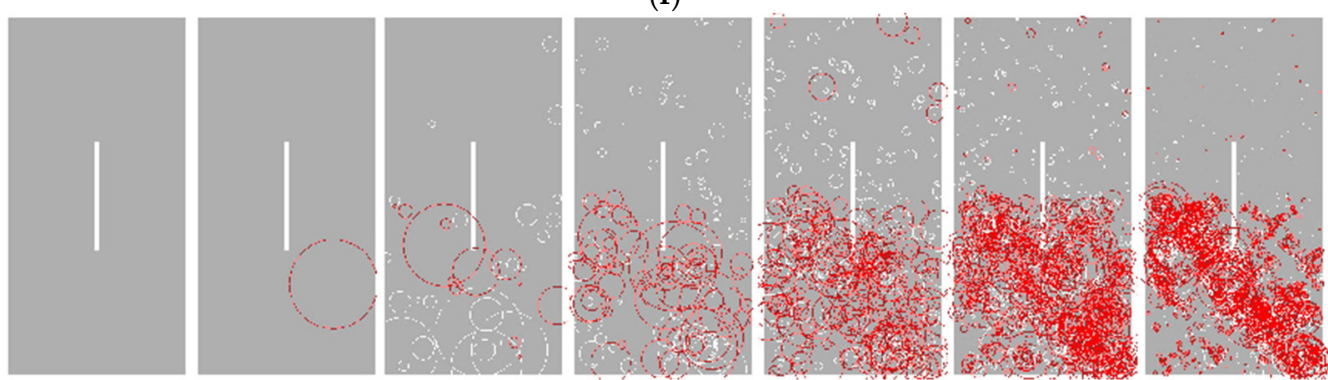

(g)

Figure 9. Cont. 

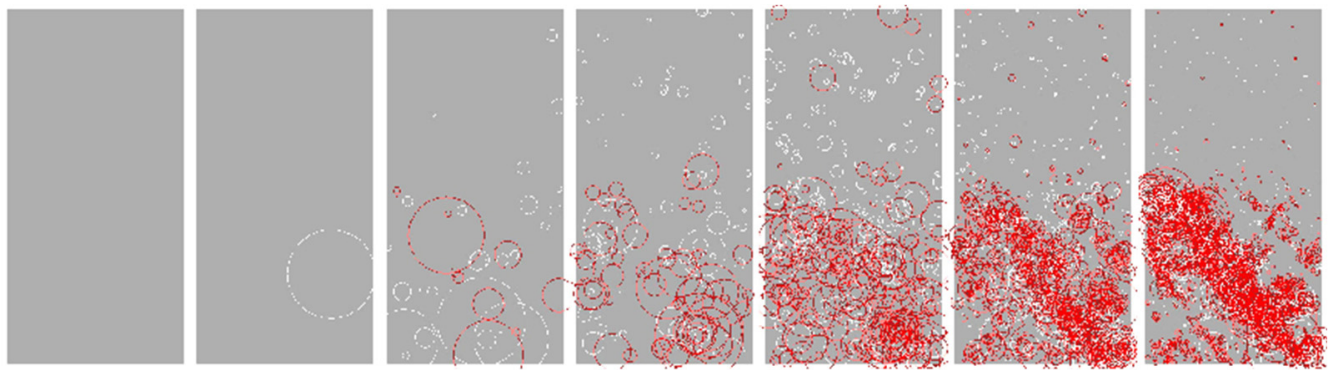

(h)

Figure 9. Acoustic emission evolution behaviors of coal-rock combined body: $(\mathbf{a}) \theta=0^{\circ}$; (b) $\theta=15^{\circ}$; (c) $\theta=30^{\circ}$; (d) $\theta=45^{\circ}$; (e) $\theta=60^{\circ}$; (f) $\theta=75^{\circ}$; (g) $\theta=90^{\circ}$; (h) intact specimens.

\section{Mechanical Properties and Failure Modes of Coal-Rock Combined Body with Different Prefabricated Crack Angles}

\subsection{Influence of Crack Angle on Unconfined Compressive Strength}

Figure 10 illustrates the change in the unconfined compressive strength (UCS) of the coal-rock combined body with the increase in the prefabricated crack angle. It can be observed that the UCS first decreased linearly from $11.6 \mathrm{MPa}$ at $\theta=0^{\circ}$ to $4.1 \mathrm{Mpa}$ at $\theta=45^{\circ}$ and then increased linearly to $10.2 \mathrm{MPa}$ at $\theta=90^{\circ}$. Therefore, the curve of UCS versus the prefabricated crack angle can be regarded as a $\mathrm{V}$ shape. It should also be noted that the UCS of the coal-rock combined body at $\theta=0^{\circ}$ was even slightly larger than that of the intact specimen (approximately $11 \mathrm{MPa}$ ).

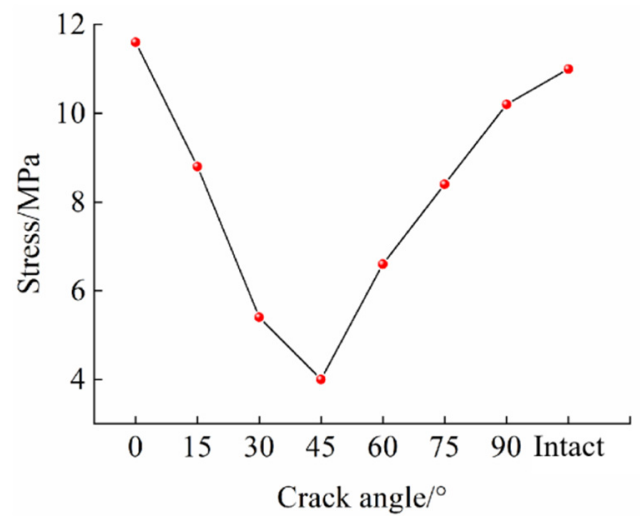

Figure 10. Acoustic emission evolution behaviors of coal-rock combined body.

The variation in this strength with the increase in the prefabricated crack angle was related to the shear failure angle of the coal-rock combined body. Additionally, the stress analysis of the combined body with a prefabricated crack is shown in Figure 11. According to the Mohr-Coulomb failure criterion, the normal stress $\sigma$ and shear stress $\tau$ acting on the fracture can be expressed as follows:

$$
\begin{gathered}
\sigma=\frac{1}{2}\left(\sigma_{1}+\sigma_{3}\right)+\frac{1}{2}\left(\sigma_{1}-\sigma_{3}\right) \cos 2 \theta \\
\tau=\frac{1}{2}\left(\sigma_{1}-\sigma_{3}\right) \sin 2 \theta
\end{gathered}
$$

where $\sigma_{1}$ is the maximum principal stress, $\sigma_{3}$ is the minimum principal stress and $\theta$ is the angle between the minimum principal stress and the prefabricated crack. Additionally, the minimum principal stress was equal to 0 in this study. Substituting it into Equations (1) and (2), the following expressions can be formulated:

$$
\sigma=\sigma_{1} \cos ^{2} \theta
$$




$$
\tau=\frac{1}{2} \sigma_{1} \sin 2 \theta
$$

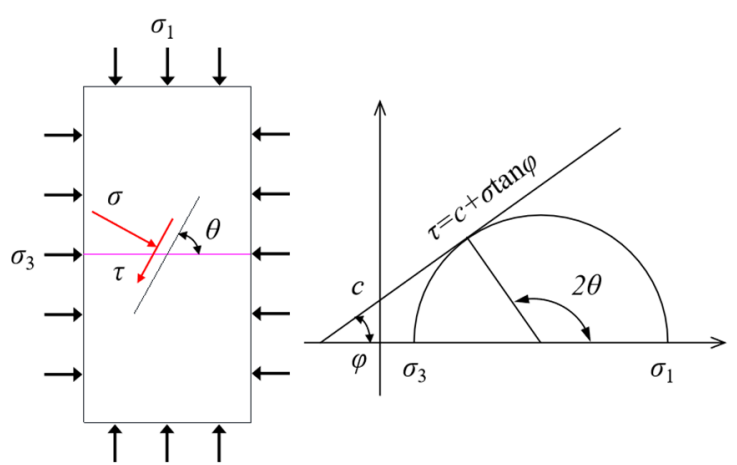

Figure 11. Strength analysis of single crack plane.

When the specimen fails along the crack, it satisfies the following criterion:

$$
\tau=c+\sigma \tan \varphi
$$

Based on the above description, the maximum principal stress meets the following expression when the specimen undergoes sliding failure.

$$
\sigma_{1}=\frac{2 c}{(1-\tan \varphi \cot \theta) \sin 2 \theta}
$$

where $c$ and $\varphi$ are cohesion and the internal friction angle, respectively.

When the specimen fails along the crack plane, the angle $(\theta)$ between the minimum principal stress and the prefabricated crack can be expressed as follows:

$$
\theta=\frac{\pi}{4}+\frac{\varphi}{2}
$$

In this study, the internal friction angles of the mudstone and coal were $30^{\circ}$ and $25^{\circ}$, respectively. According to Equation (7), it can be inferred that the coal-rock combined body with a prefabricated crack is most likely to undergo sliding failure along the crack plane when the prefabricated crack angle is in the range from $57.5^{\circ}$ to $60^{\circ}$, which is basically consistent with the experimental test results.

\subsection{Failure Modes}

\subsubsection{Influence of Crack Angle on Failure Modes}

Combined with the results of the experimental tests and numerical simulation, the failure modes and acoustic emission diagrams of the coal-mudstone combined body with different prefabricated crack angles (e.g., $0^{\circ}, 15^{\circ}, 30^{\circ}, 45^{\circ}, 60^{\circ}, 75^{\circ}$ and $90^{\circ}$ ) are shown in Figure 12. Additionally, a group of intact coal-mudstone combined bodies was added as a reference. This illustrates that the failure of the lower coal body mainly caused the whole failure of the coal-mudstone combined body, and only a few cracks were generated around the upper tip of the prefabricated crack in the rock body. It can be stated that the resistance strength of the coal mass was mostly small, and its homogeneous degree was low, causing the breakage of the lower coal body first in the initial axial loading process. With the continuous loading, only a few cracks formed in the upper rock body, with larger resistance strength and a higher homogeneous degree. Overall, the strength of the whole coal-rock combined body was relatively small. Additionally, the fissure preferred to be expanded in the lower coal body. Moreover, the stress concentration can also cause the generation of a few new cracks near the prefabricated crack tip in the upper mudstone body. 
In terms of the intact specimen, the failure mode could be regarded mainly as shear failure in the lower coal body. However, the failure modes of the coal-rock combined body with a prefabricated crack could be divided into three types based on the values of the prefabricated crack angle. At $\theta=0^{\circ}$, the main shear failure of the lower coal body was also the dominant factor causing the whole failure of the coal-rock combined body. The failure direction was perpendicular to the direction of the maximum principal stress, and the failure cracks were symmetrical to the central axis, as shown in Figure 12a. Additionally, an octagonal airfoil-shaped crack was observed at the prefabricated crack tip in the lower coal body, while there were only a few cracks in the upper mudstone body. With the increase in the prefabricated crack angle (e.g., $15-75^{\circ}$ ), the failure mode could be regarded as an octagonal airfoil-shaped crack rotating clockwise. Moreover, the higher side crack in the lower coal body was connected to the crack in the upper mudstone body, resulting in a long crack through the whole coal-rock combined body. Additionally, it was more obvious when the prefabricated crack angle was in the range from $15^{\circ}$ to $75^{\circ}$, as shown in Figure $12 \mathrm{~b}-\mathrm{f}$. It can be stated that the shear failure angle of most cracks was concentrated in these angle ranges. The failure mode in the range of crack angles from $15^{\circ}$ to $75^{\circ}$ was coal-rock mixed tensile-shear failure, and it was easy to produce "reverse airfoil crack behaviors". At $\theta=90^{\circ}$, the prefabricated crack angle was almost parallel to the loading axis. Additionally, the failure mode was basically consistent with that of the intact coal-mudstone combined body, in which shear failure cracks could be observed in the lower coal body, and only a few cracks occurred in the upper mudstone body, as shown in Figure 12g. Therefore, the failure mode under this condition was mainly shear failure.
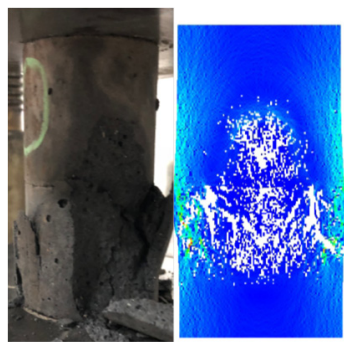

(a)
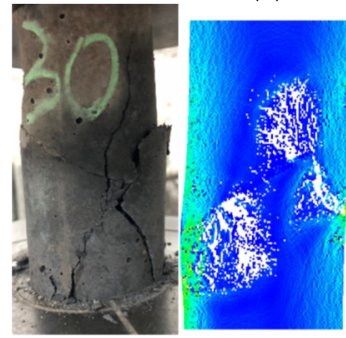

(c)
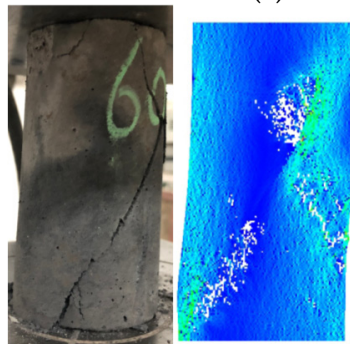

(e)
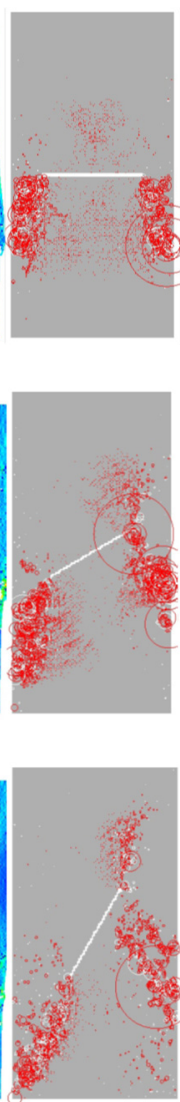
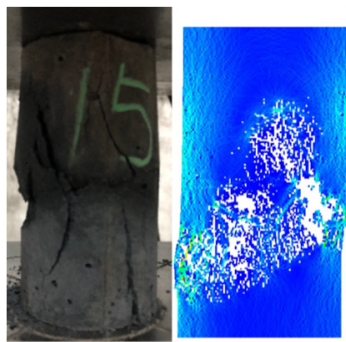

(b)
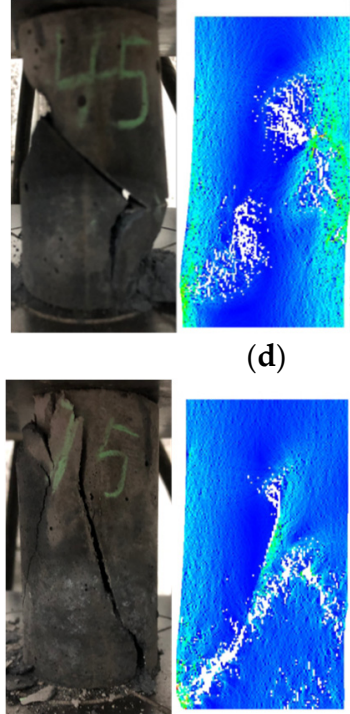

(d)

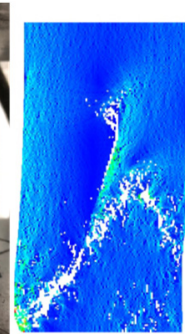

(f)
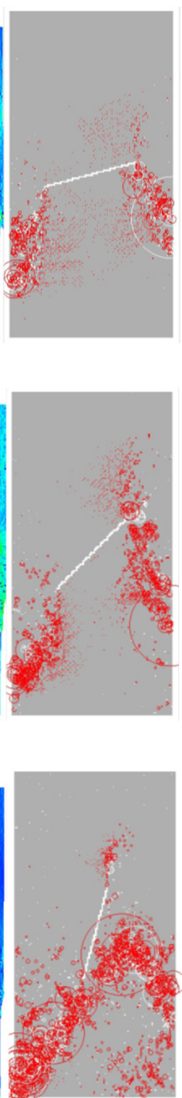

Figure 12. Cont. 

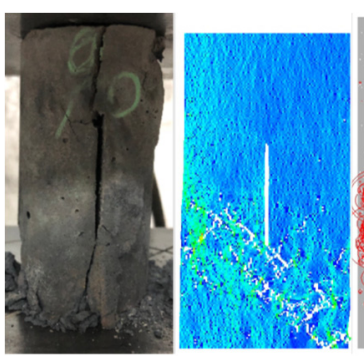

(g)
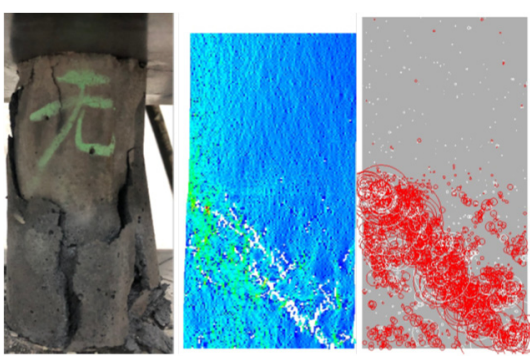

(h)

Figure 12. Failure modes of coal-rock combination body with different prefabricated crack angles: (a) $\theta=0^{\circ}$; (b) $\theta=15^{\circ}$; (c) $\theta=30^{\circ}$; (d) $\theta=45^{\circ}$; (e) $\theta=60^{\circ}$; (f) $\theta=75^{\circ}$; (g) $\theta=90^{\circ}$; (h) intact specimen.

\subsubsection{Reverse Airfoil Crack Behaviors}

Throughout the literature, the crack propagation of rock-like materials at the crack tip is divided into airfoil cracks and secondary cracks under unconfined compression conditions [41]. Airfoil cracks initially germinate at the crack tip with a certain angle and develop towards the direction of the maximum principal stress. Generally, the airfoil cracks of the rock specimen with the occurrence of a prefabricated crack were distributed in the upper and lower directions of the prefabricated crack and were roughly parallel to the direction of the loading force under unconfined compression conditions. In terms of the coal-rock combined body, different airfoil cracks could be observed, where, although the airfoil cracks initially germinated at the tip of the prefabricated crack, two main cracks were distributed on one side of the prefabricated crack. Due to the upper part of the prefabricated crack in the mudstone body having higher strength, the two crack tips generated reverse airfoil cracks with the continuous loading. Moreover, the cracks tended to expand in the direction of the lower coal body with lower strength, as shown in Figure 13. Obviously, when $\theta=0^{\circ}-75^{\circ}$, a "reverse airfoil crack" was prone to occur.

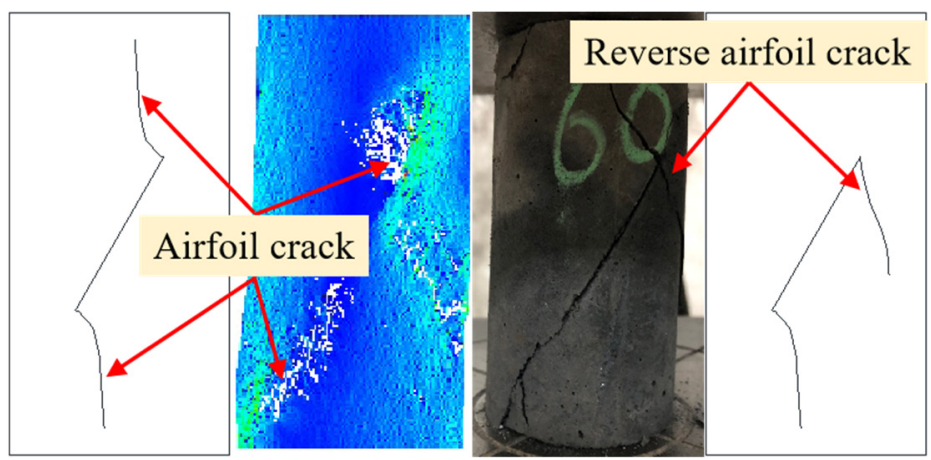

Figure 13. Airfoil cracks and reverse airfoil cracks.

\section{Conclusions}

To study the influence of the prefabricated crack angle on the mechanical characteristics, acoustic emission and failure modes of a coal-rock combined body, experimental tests and numerical simulation were performed on a coal-mudstone combined body with prefabricated crack angles of $0^{\circ}, 15^{\circ}, 30^{\circ}, 45^{\circ}, 60^{\circ}, 75^{\circ}$ and $90^{\circ}$. The following conclusions can be drawn from the current study.

(1) The occurrence of a prefabricated crack and its angle had limited effect on the elastic modulus of the coal-rock combined body, while the axial strain corresponding to the failure and instability status of the coal-rock combined body with the occurrence of a prefabricated crack was smaller than that of the intact specimen. Additionally, this axial strain decreased first and then increased with the increase in the prefabricated 
crack angle. In addition, all of the stress-strain curves of the coal-mudstone combined body showed the secondary elastic deformation stage.

(2) The unconfined compressive strength of the coal-rock combined specimen decreased first and then increased with the increase in the prefabricated crack angle. Additionally, the lowest unconfined compressive strength of the coal-mudstone combined body was obtained at the prefabricated crack angle of $45^{\circ}$. Moreover, the unconfined compressive strength of the coal-mudstone combined body with the prefabricated crack angle of $0^{\circ}$ was even slightly larger than that of the intact specimen.

(3) At the initial loading stage, the stress reduction zone and the acoustic emission appeared in both ends of the prefabricated crack, while the rest areas were high-stress zones. With the process of continuous loading, the high- and low-stress zones were transformed. Moreover, stress concentration zones were formed in both ends of the prefabricated crack. The acoustic emission became more obvious, and the number of acoustic emissions increased. After that, the high-stress zone continued to expand with the expansion of the prefabricated crack.

(4) When the prefabricated crack angle was relatively small, tensile failure mainly occurred around the crack and in the lower coal body, while shear failure was distributed in the whole specimen. On the other hand, shear failure could be mainly observed in the lower coal body, and the distribution of tensile failure was more uniform in the whole specimen when the prefabricated crack angle was relatively large. The failure of the coal-mudstone combined body was mainly caused by the failure of the lower coal body, while only a few airfoil cracks or reverse airfoil cracks could be observed in the upper tip of the prefabricated crack in the mudstone body.

Author Contributions: H.L.: formal analysis, numerical simulation, experimental test, writingoriginal draft, funding acquisition; D.W.: formal analysis, investigation; Z.C.: formal analysis, methodology, validation, writing, review and editing; Y.Z.: formal analysis, numerical simulation, experimental test, methodology, writing—original draft; T.Z.: writing—original draft. All authors have read and agreed to the published version of the manuscript.

Funding: This research was funded by the Research Startup Budget Funding Project of Shangqiu Normal University (Grant No. 700167), the Innovation and Entrepreneurship Training Program for College Students in Henan Province (Grant No. S202110483040) and the China Scholarship Council (Grant No. 201706430044). The authors would also like to thank the editors and anonymous reviewers for their valuable time and suggestions.

Institutional Review Board Statement: Not applicable.

Informed Consent Statement: Not applicable.

Data Availability Statement: All data used during the study appear in the submitted article.

Conflicts of Interest: The authors declare no conflict of interest.

\section{References}

1. Kong, D.; Cheng, Z.; Zheng, S. Study on the failure mechanism and stability control measures in a large-cutting-height coal mining face with a deep-buried seam. Bull. Eng. Geol. Environ. 2019, 78, 6143-6157. [CrossRef]

2. Xiong, Y.; Kong, D.; Cheng, Z.; Wu, G.; Zhang, Q. The Comprehensive Identification of Roof Risk in a Fully Mechanized Working Face Using the Cloud Model. Mathematics 2021, 9, 2072. [CrossRef]

3. Liu, F.; Guo, Z.; Lv, H.; Cheng, Z. Test and analysis of blast wave in mortar test block. Int. J. Rock Mech. Min. Sci. 2018, 108, 80-85. [CrossRef]

4. Kong, D.; Xiong, Y.; Cheng, Z.; Wang, N.; Wu, G.; Liu, Y. Stability analysis of coal face based on coal face-support-roof system in steeply inclined coal seam. Geomech. Eng. 2021, 25, 233-243. [CrossRef]

5. Guo, Q.; Pan, J.; Cai, M.; Zhang, Y. Investigating the effect of rock bridge on the stability of locked section slopes by the direct shear test and acoustic emission technique. Sensors 2020, 20, 638. [CrossRef]

6. Lee, H.; Jeon, S. An experimental and numerical study of fracture coalescence in pre-cracked specimens under uniaxial compression. Int. J. Solid Struct. 2011, 48, 979-999. [CrossRef]

7. Lv, H.; Cheng, Z; Dong, Y.; Zhang, J.; Ma, Y. Numerical simulation on the crack initiation and propagation of coal with combined defects. Struct. Eng. Mech. 2021, 79, 237-245. [CrossRef] 
8. Xiong, Y.; Kong, D.; Cheng, Z.; Wen, Z.; Ma, Z.; Wu, G.; Liu, Y. Instability Control of Roadway Surrounding Rock in Close-Distance Coal Seam Groups under Repeated Mining. Energies 2021, 14, 5193. [CrossRef]

9. Zhao, Y.; Gong, S.; Zhang, C.; Zhang, Z.; Jiang, Y. Fractal characteristics of crack propagation in coal under impact loading. Fractals 2018, 26, 1840014. [CrossRef]

10. Li, D.; Wang, E.; Kong, X.; Ali, M.; Wang, D. Mechanical behaviors and acoustic emission fractal characteristics of coal specimens with a pre-existing flaw of various inclinations under uniaxial compression. Int. J. Rock Mech. Min. 2019, 116, 38-51. [CrossRef]

11. Zhang, Y.; Cheng, Z.; Lv, H. Study on failure and subsidence law of frozen soil layer in coal mine influenced by physical conditions. Geomech. Eng. 2019, 18, 97-109. [CrossRef]

12. Liu, X.; Cheng, Z. Changes in subsidence-field surface movement in shallow-seam coal mining. J. S. Afr. Inst. Min. Metall. 2019, 119, 201-206. [CrossRef]

13. Lv, H.; Cheng, Z.; Liu, F. Study on the mechanism of a new fully mechanical mining method for extremely thick coal seam. Int. J. Rock Mech. Min. Sci. 2021, 142, 104788. [CrossRef]

14. Cheng, Z.; Geng, X. Soil consistency and interparticle characteristics of various biopolymer types stabilization of clay. Geomech Eng. 2021, 27, 103-113. [CrossRef]

15. Dong, W.; Wu, Z.; Zhou, X.; Wang, N.; Kastiukas, G. An experimental study on crack propagation at rock-concrete interface using digital image correlation technique. Eng. Fract. Mech. 2017, 171, 50-63. [CrossRef]

16. Aria, M.; Riccardo, S.; Andrea, M.; Marco, G. Testing and numerical simulation of a medium strength rock material under unconfined compression loading. J. Rock Mech. Geotech. 2018, 10, 5-19. [CrossRef]

17. Beráková, A.; Melichar, R.; Souek, K. Mechanical properties and failure patterns of migmatized gneiss with metamorphic foliation under UCS test. Rock Mech. Rock Eng. 2020, 53, 2007-2013. [CrossRef]

18. Wong, R.H.C.; Chau, K.T. Crack coalescence in a rock-like material containing two cracks. Int. J. Rock Mech. Min. 1998, 35, 147-164. [CrossRef]

19. Wong, R.H.C.; Chau, K.T.; Tang, C.A.; Lin, P. Analysis of crack coalescence in rock-like materials containing three flaws-Part I: Experimental approach. Int. J. Rock Mech. Min. Sci. 2001, 38, 909-924. [CrossRef]

20. Li, D.; Han, Z.; Sun, X.; Li, X. Characteristics of dynamic failure of marble with artificial flaws under split Hopkinson pressure bar tests. Chin. J. Rock Mech. Eng. 2017, 36, 2872-2883.

21. Yang, S.; Yang, Z.; Zhang, P.; Tian, W. Experiment and peridynamic simulation on cracking behavior of red sandstone containing a single non-straight fissure under uniaxial compression. Theor. Appl. Fract. Mech. 2020, 108, 102637. [CrossRef]

22. Li, S.; Zhang, D.; Bai, X.; Zhang, X.; Chu, Y.; Guo, K. Experimental study on mechanical properties, acoustic emission energies and failure modes of pre-cracked rock materials under uniaxial compression. Pure Appl. Geophys. 2019, 176, 4519-4532. [CrossRef]

23. Tang, C. Analysis of crack coalescence in rock-like materials containing three flaws-Part II: Numerical approach. Int. J. Rock Mech. Min. Sci. 2001, 38, 925-939. [CrossRef]

24. Sun, W.; Du, H.; Zhou, F.; Shao, J. Experimental study of crack propagation of rock-like specimens containing conjugate fractures. Geomech. Eng. 2019, 17, 323-331. [CrossRef]

25. Lv, H.; Tang, Y.; Zhang, L.; Cheng, Z.; Zhang, Y. Analysis for mechanical characteristics and failure models of coal specimens with non-penetrating single crack. Geomech. Eng. 2019, 17, 355-365. [CrossRef]

26. Yang, S.; Yin, P.; Zhang, Y.; Chen, M.; Zhou, X.; Jing, H.; Zhang, Q. Failure behavior and crack evolution mechanism of a non-persistent jointed rock mass containing a circular hole. Int. J. Rock Mech. Min. Sci. 2019, 114, 101-121. [CrossRef]

27. Zeng, W.; Yang, S.; Tian, W. Experimental and numerical investigation of brittle sandstone specimens containing different shapes of holes under uniaxial compression. Eng. Fract. Mech. 2018, 200, 430-450. [CrossRef]

28. Petukhov, I.; Linkov, A. The theory of post-failure deformations and the problem of stability in rock mechanics. Int. J. Rock Mech. Min. Sci. Geomech. Abstr. 1979, 16, 57-76. [CrossRef]

29. Wang, S.; Sloan, S.; Sheng, D. Numerical study of failure behaviour of pre-cracked rock specimens under conventional triaxial compression. Int. J. Solids Struct. 2014, 51, 1132-1148. [CrossRef]

30. Zuo, J.; Chen, Y.; Cui, F. Investigation on mechanical properties and rock burst tendency of different coal-rock combined bodies. J. China Univ. Min. Technol. 2018, 47, 81-87.

31. Xie, H.; Chen, Z.; Zhou, H.; Cheng, Y.; Chen, Z. Study on two-body mechanical model based on interaction between structural body and geo-body. Chin. J. Rock Mech. Eng. 2005, 24, 1457-1464.

32. Zhao, Y.; Jiang, Y.; Han, Z. Experimental study on acoustic and thermal infrared characteristics of bump-prone coal. Chin. J. Rock Mech. Eng. 2007, 26, 965-971.

33. Gong, F.; Ye, H.; Luo, Y. The effect of high loading rate on the behaviour and mechanical properties of coal-rock combined body Shock Vib. 2018, 4374530. [CrossRef]

34. Cheng, Z.; Li, L.; Zhang, Y. Laboratory investigation of the mechanical properties of coal-rock combined body. Bull. Eng. Geol. Environ. 2020, 79, 1947-1958. [CrossRef]

35. Wang, X.; Tian, L. Mechanical and crack evolution characteristics of coal-rock under different fracture-hole conditions: A numerical study based on particle flow code. Environ. Earth Sci. 2018, 77, 297. [CrossRef]

36. Liu, X.; Tan, Y.; Ning, J.; Lu, Y.; Gu, Q. Mechanical properties and damage constitutive model of coal in coal-rock combined body. Int. J. Rock Mech. Min. Sci. 2018, 110, 140-150. [CrossRef] 
37. Tan, Y.; Liu, X.; Shen, B.; Ning, J.; Gu, Q. New approaches to testing and evaluating the impact capability of coal seam with hard roof and/or floor in coal mines. Geomech. Eng. 2018, 4, 367-376. [CrossRef]

38. Cheng, Z.; Pan, W.; Li, X.; Sun, W. Numerical simulation on strata behaviours of TCCWF influenced by coal-rock combined body. Geomech. Eng. 2019, 19, 269-282. [CrossRef]

39. Cheng, Z.; Yang, S.; Li, L.; Zhang, L. Support working resistance determined on top-coal caving face based on coal-rock combined body. Geomech. Eng. 2019, 19, 255-268. [CrossRef]

40. Liu, J.; Tang, C.; Zhu, W.; Yang, T. Rock-coal model for studying the rockburst. Chin. J. Geotech. Eng. 2004, 26, $276-280$.

41. Jin, J.; Cao, P.; Pu, C. Influence of flaw parameters on damage mode and strength of rock-like materials. J. Cent. South Univ. (Sci. Technol.) 2014, 45, 529-535. 